\title{
Spontaneous Rectal Perforation in a Patient with SARS-CoV-2 Infection
}

\author{
Mauro Giuffrè ${ }^{1,2, *,+}\left(\mathbb{C}\right.$, Alessandro Marco Bozzato ${ }^{1,+} \mathbb{C}^{\mathbb{C}}$, Stefano Di Bella ${ }^{1}(\mathbb{D}$, \\ Alessandro Agostino Occhipinti ${ }^{3}$, Paola Martingano ${ }^{4}$, Marco Francesco Maria Cavallaro ${ }^{4}$, \\ Roberto Luzzati ${ }^{1}$, Fabio Monica ${ }^{5}$, Maria Assunta Cova ${ }^{1}$ and Lory Saveria Crocè ${ }^{1,2}$ (D) \\ 1 Department of Medical, Surgical and Health Sciences, University of Trieste, 34151 Trieste, Italy; \\ alessandroj.bozzato@gmail.com (A.M.B.); stefano932@gmail.com (S.D.B.); \\ roberto.luzzati@asuits.sanita.fvg.it (R.L.); m.cova@fmc.units.it (M.A.C.); lcroce@units.it (L.S.C.) \\ 2 Italian Liver Foundation, 34149 Basovizza Trieste, Italy \\ 3 Emergency Department, Trieste University Hospital, 34139 Trieste, Italy; alexander82@tiscali.it \\ 4 Department of Radiology, Trieste University Hospital, 34139 Trieste, Italy; pmartingano@sirm.org (P.M.); \\ marcofrancescomaria.cavallaro@asugi.sanita.fvg.it (M.F.M.C.) \\ 5 Department of Gastroenterology, Trieste University Hospital, 34139 Trieste, Italy; \\ fabio.monica@asuits.sanita.fvg.it \\ * Correspondence: mauro.giuffre@fegato.it; Tel.: +39-0403994044; Fax: +39-0403994226 \\ + These two authors contributed equally to the present work.
}

Received: 20 September 2020; Accepted: 28 September 2020; Published: 8 October 2020

\begin{abstract}
Coronavirus disease 2019 (COVID-19) is mostly perceived as a respiratory disease. However, there is increasing evidence of patients showing gastrointestinal symptoms, with increasing rates of presentation according to the severity of the disease. In a few cases, the abdominal involvement of COVID-19 resulted in spontaneous bowel perforation. Here, we present in detail the first case of rectal perforation in a patient with COVID-19.
\end{abstract}

Keywords: COVID-19; SARS-CoV-2; fecal calprotectin; bowel perforation; radiology COVID-19

\section{Introduction}

At the time of writing the present report, the leading cause of SARS-CoV-2-related mortality is respiratory failure, and coronavirus disease 2019 (COVID-19) is mostly perceived as a respiratory disease [1-3]. However, COVID-19 has significant extrapulmonary complications. In particular, gastrointestinal symptoms appear to affect $28 \%$ of patients with COVID-19 [4], with increasing rates of presentation according to the severity of the disease [5]. Additional findings include the detection of fecal viral RNA in around 50\% of patients [6-8], the measurement of increased fecal calprotectin (FC) in patients, with or without gastrointestinal symptoms $[9,10]$, and the detection of bowel wall abnormalities in $31 \%$ of computed tomography $(\mathrm{CT})$ performed on patients with COVID-19 [11]. In a few cases, the abdominal involvement of COVID-19 resulted in spontaneous bowel perforation [9,11-13], and, to the best of our knowledge, no rectal perforation has ever been described before. Here, we present, in detail, the first case of rectal perforation in a patient with COVID-19.

\section{Case Report}

An 87-year-old woman living in a nursing home was admitted to the emergency department with abdominal pain, cough, and high-grade fever, which had started four days prior to hospital admission. 
Her past medical history included polymyalgia rheumatica, giant cell arteritis, and slight cognitive impairment. She had no previous history of abdominal surgery nor gastrointestinal symptoms. The patient did not report any contact with people at high-risk for SARS-CoV-2 infection. However, real-time PCR of nasopharyngeal swab tested positive for SARS-CoV-2.

On admission, her blood pressure was $100 / 60 \mathrm{mmHg}$, her pulse was $100 \mathrm{bpm}$ rhythmic, and $\mathrm{SatO}_{2}$ was $95 \%$ in ambient air and $97 \%$ in $\mathrm{O}_{2}$ at $40 \%$.

Physical examination of the chest revealed a reduction of murmur to the pulmonary bases, bilaterally. In addition, the whole abdomen appeared distended, diffusely tender, and positive for Blumberg's sign. Bowel sounds were not audible. Moreover, a rectal examination revealed rectorrhagia.

Laboratory tests were as follows: white blood cell count 5990 cells $/ \mathrm{mm}^{3}$, hemoglobin $15 \mathrm{~g} / \mathrm{dL}$, platelet count $233.00010^{9} / \mathrm{L}$, C-reactive protein $290 \mathrm{mg} / \mathrm{dL}$, INR 1.22, aPTT $29.2 \mathrm{~s}$, fibrinogen $790 \mathrm{mg} / \mathrm{dL}$, D-Dimer $2.1 \mathrm{mg} / \mathrm{LFEU}$, fecal calprotectin $290 \mathrm{mg} / \mathrm{kg}$. Renal, liver, and pancreatic function tests were within the range of normality.

During clinical monitoring, the patient experienced a rapid deterioration of clinical conditions, with the development of septic shock, and so a contrast-enhanced CT of the chest and the abdomen was performed. The abdominal CT showed wall thickening of the lower third of the rectum associated with free perivisceral air (Figure 1), findings suggestive of rectal perforation; perivisceral fat stranding and thickening of the mesorectal fascia were also seen (Figure 2). On the chest CT, typical imaging features of COVID-19 interstitial pneumonia were clearly visible, with patchy bilateral ground-glass opacities associated with interlobular and intralobular septal thickening (Figure 3).

Unfortunately, the patient died $12 \mathrm{~h}$ after admission to the hospital.

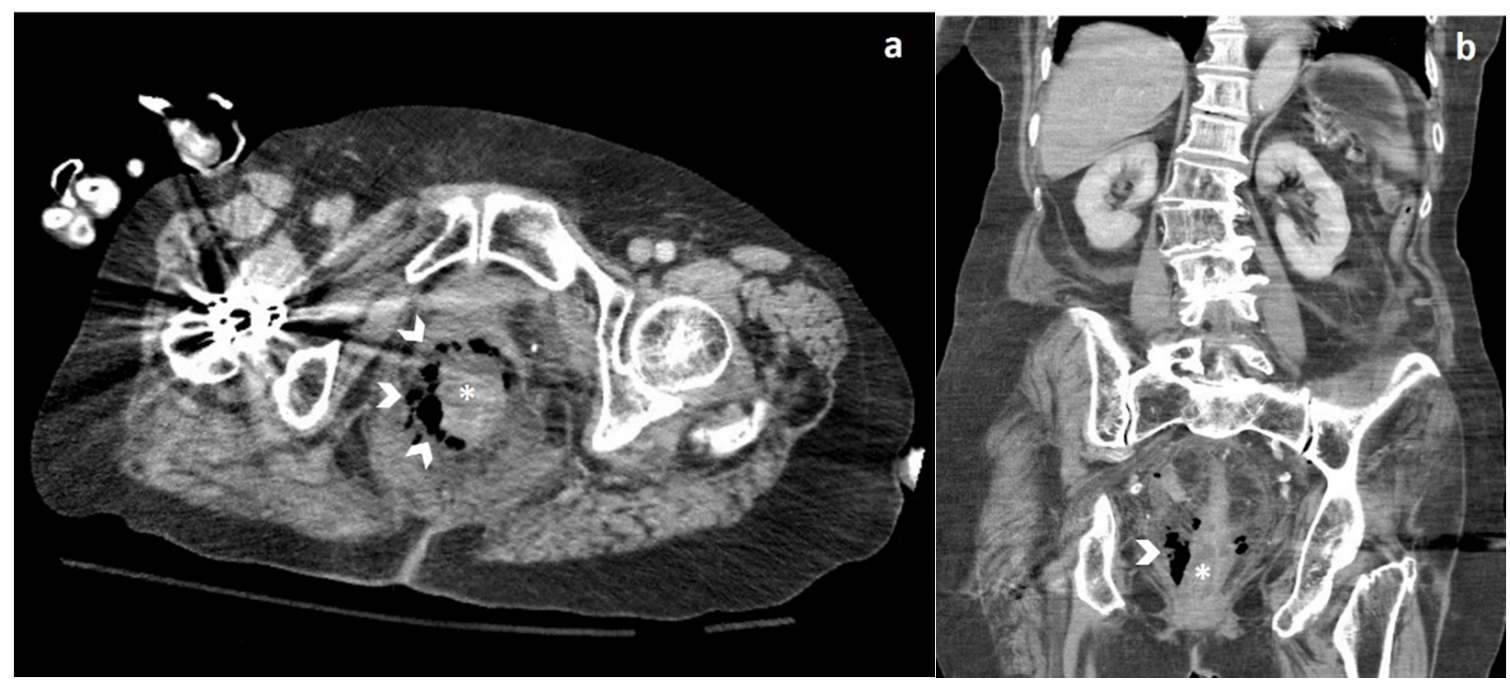

Figure 1. Axial (a) and coronal (b) computed tomography (CT) images show wall thickening (asterisk) of the lower-third of the rectum, surrounded by extraluminal free air (arrowheads). 

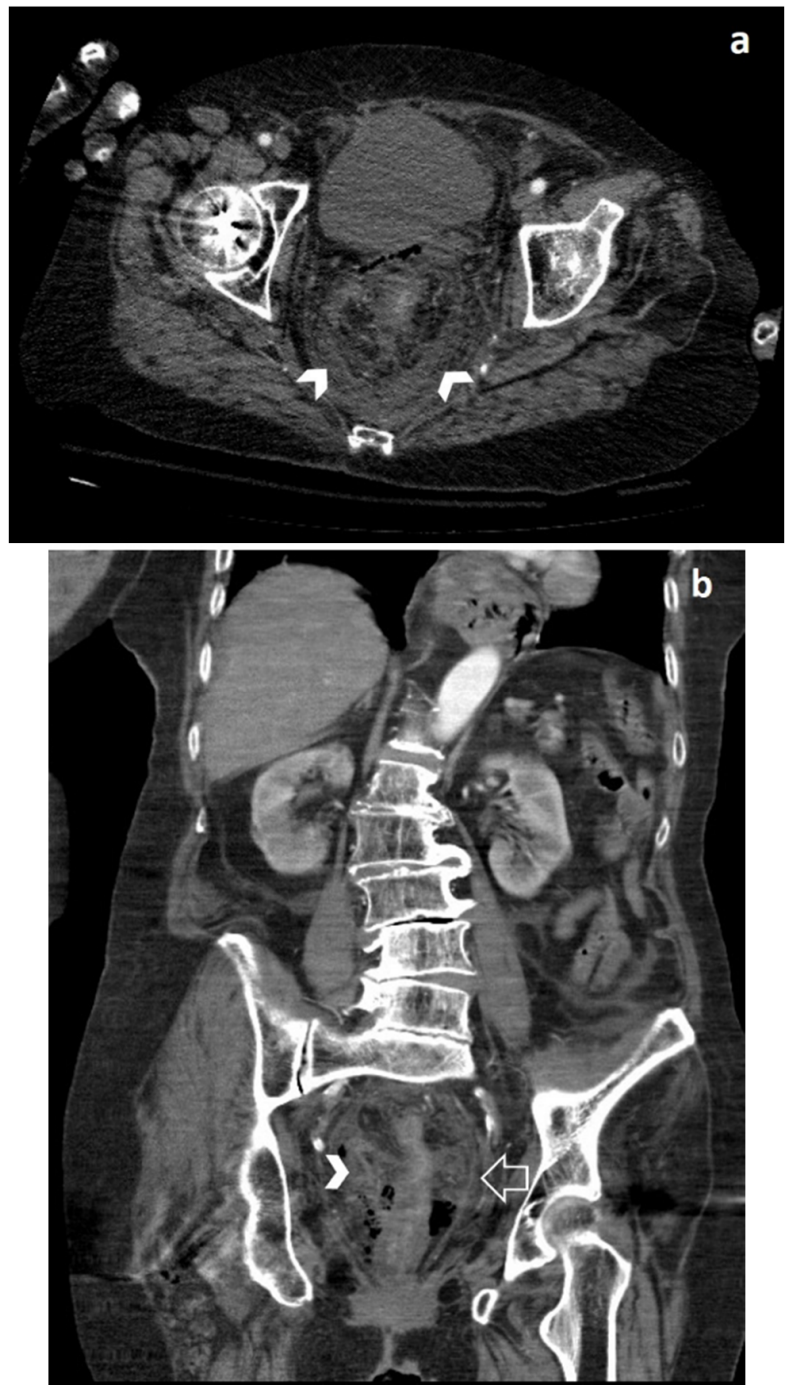

Figure 2. Axial (a) and coronal (b) CT images show perivisceral fat stranding (arrowheads) and thickening of the mesorectal fascia (open arrow in (b)).

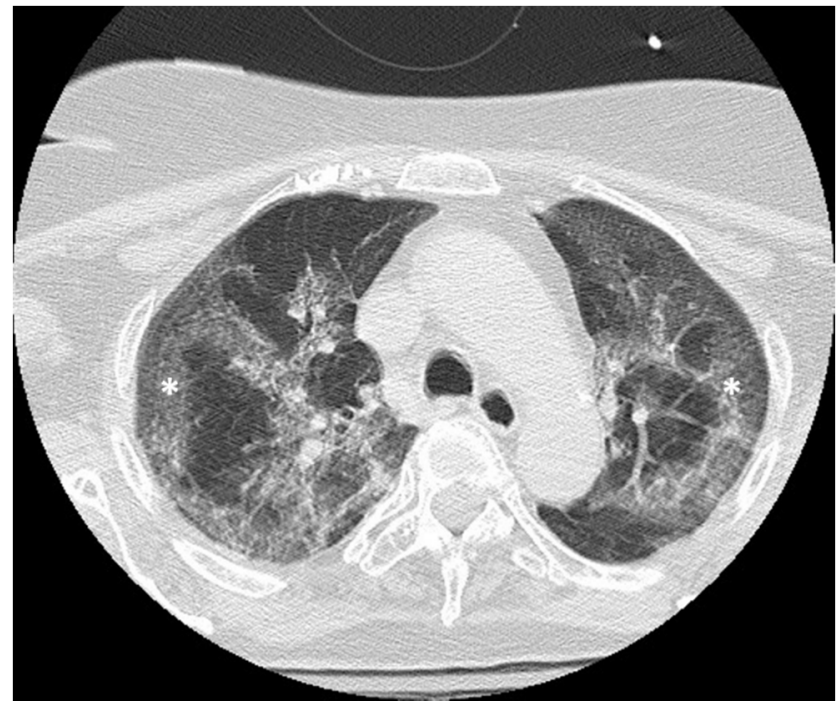

Figure 3. Axial CT image shows ground-glass opacity superimposed by interlobular and intralobular septal thickening (asterisk). 


\section{Discussion}

Large bowel perforation is an abdominal emergency, with an overall mortality of 16.9-19.6\% [14]. Etiologies are usually divided into two macrocategories: traumatic vs. spontaneous, which occur due to excessive straining on the anterior rectal wall with a pre-existing condition, such as malignancy, stercoral colitis, ischemic colitis, diverticulitis, inflammatory bowel disease, or infective diseases.

$\mathrm{CT}$ is the most valuable imaging technique for identifying the presence, site, and cause of bowel perforation, with an overall accuracy ranging from $82 \%$ to $90 \%$ [15]. The imaging diagnosis of bowel perforation almost always relies on the detection of free extraluminal air. Although the perforation is often distant from free extraluminal air, the presence of concentrated free air bubbles surrounding a bowel loop is a highly predictive sign for the perforation site. The location of extraluminal air from a rectal perforation depends on its site because the upper two-thirds of the rectum are intraperitoneal, whereas the lower third is extraperitoneal, so free intraperitoneal gas is usually seen if the perforation site is located in the upper two-thirds of the rectum, while if it is located in the lower third, free air may be present in the retroperitoneal space [16]. In addition, focal bowel wall discontinuity, sometimes associated with wall thickening and increased attenuation of the surrounding fat, the so-called "fat stranding", could be seen. However, the perforation site is visible only in few cases, more often in the upper gastrointestinal tract than in the lower one $[15,16]$.

Lack of bowel wall enhancement, pneumatosis intestinalis, and portomesenteric gas are suggestive of underlying bowel ischemia [15-18].

Possible causes of COVID-19-related bowel perforation may be related to (1) direct viral infection, given its interaction with the ACE-2 receptors of enterocytes; (2) small vessel thrombosis due to the direct inflammatory effect on vascular endothelium; (3) nonocclusive mesenteric ischemia, which was first hypothesized after values of FC compatible with ischemic bowel disease were detected in COVID-19 patients without gastrointestinal symptoms [8]. According to their anatomy, left flexure and sigmoid colon segments have the highest risk of ischemic colitis, while the distal rectum is usually spared due to its dual blood supply. Of note, bowel wall thickening was detected in $29 \%$ of patients with COVID-19, with the colorectal districts being the most affected [11].

In the case herein described, the exact pathophysiological process could not, unfortunately, be determined due to the lack of surgical/bioptical and autopsy samples. However, Bhayana et al. [11] reported a frank discontinuity of a small bowel loop with pneumatosis and a nonenhancing bowel wall on the CT scan, and bowel necrosis with an atypical yellow discoloration of the loops was confirmed by laparotomy. Additionally, in the case reported by Gartland et al. [13], a CT scan showed small bowel ischemia with perforation (but patency of the mesenteric vessels), and, upon surgical examination, a necrotic bowel extending from the ligament of Treitz to the transverse colon, with a perforated terminal ileum. The necrosis, as also described in the case of Bhayana et al., had an atypical bright yellow discoloration rather than black or purple ischemic changes.

On the other hand, in the case reported by De Nardi et al. [12], the CT scan showed free air, distension of the bowel, and the perforation site in the ascending colon. On gross examination, the bowel was enlarged with thin walls. The histological examination showed transmural granulocytic inflammation with fibrinous granulocytic perivisceritis but without vascular thrombosis.

The consistent presence of granulocytes, as reported by the two authors [11,12], may be crucial in understanding the mechanism behind the increase in FC of our patient, given that FC is mainly expressed in neutrophils. Apart from this patient, whose clinical condition deteriorated rapidly, an increase in FC was reported recently in patients without gastrointestinal symptoms or previous history of inflammatory disease [9]. According to these preliminary findings, FC should be assessed in COVID-19 patients on admission, and abdominal imaging might be performed in cases of elevated FC even without gastrointestinal symptoms.

In conclusion, emergency physicians and radiologists should be aware that rectal perforation can be a gastrointestinal manifestation of COVID-19, promptly recognizable by CT. 
Author Contributions: Conception and design: M.G., A.M.B., S.D.B., A.A.O., P.M., M.F.M.C., R.L., F.M., M.A.C., L.S.C.; extraction of clinical images: A.M.B., P.M., M.F.M.C., M.A.C.; writing and original draft preparation: M.G., A.M.B.; review, editing and approval of the final version of the manuscript: M.G., A.M.B., S.D.B., A.A.O., P.M., M.F.M.C., R.L., F.M., M.A.C., L.S.C. All authors have read and agreed to the published version of the manuscript.

Funding: The authors did not receive funding for the current work.

Conflicts of Interest: The authors declare no conflict of interest.

\section{References}

1. Sambataro, G.; Giuffrè, M.; Sambataro, D.; Palermo, A.; Vignigni, G.; Cesareo, R.; Crimi, N.; Torrisi, S.E.; Vancheri, C.; Malatino, L.; et al. The Model for Early COvid-19 Recognition (MECOR) Score: A Proof-of-Concept for a Simple and Low-Cost Tool to Recognize a Possible Viral Etiology in Community-Acquired Pneumonia Patients during COVID-19 Outbreak. Diagnostics 2020, 10, 619. [CrossRef] [PubMed]

2. Cabas, P.; Di Bella, S.; Giuffrè, M.; Rizzo, M.; Trombetta, C.; Luzzati, R.; Antonello, R.M.; Parenzan, K.; Liguori, G. Community pharmacists' exposure to COVID-19. Res. Soc. Adm. Pharm. 2020. [CrossRef] [PubMed]

3. Baratella, E.; Crivelli, P.; Marrocchio, C.; Bozzato, A.M.; De Vito, A.; Madeddu, G.; Saderi, L.; Confalonieri, M.; Tenaglia, L.; Cova, M.A. Severity of lung involvement on chest X-rays in SARS-coronavirus-2 infected patients as a possible tool to predict clinical progression: An observational retrospective analysis of the relationship between radiological, clinical, and laboratory data. J. Bras. Pneumol. 2020, 46, 1-8. [CrossRef]

4. Liang, W.; Feng, Z.; Rao, S.; Xiao, C.; Xue, X.; Lin, Z.; Zhang, Q.; Qi, W. Diarrhoea may be underestimated: A missing link in 2019 novel coronavirus. Gut 2020, 69, 1141-1143. [CrossRef] [PubMed]

5. El Moheb, M.; Naar, L.; Christensen, M.A.; Kapoen, C.; Maurer, L.R.; Farhat, M.; Kaafarani, H.M.A. Gastrointestinal Complications in Critically Ill Patients With and Without COVID-19. JAMA 2020. [CrossRef] [PubMed]

6. Xiao, F.; Tang, M.; Zheng, X.; Liu, Y.; Li, X.; Shan, H. Evidence for Gastrointestinal Infection of SARS-CoV-2. Gastroenterology 2020, 158, 1831-1833. [CrossRef] [PubMed]

7. Lin, L.; Jiang, X.; Zhang, Z.; Huang, S.; Zhang, Z.; Fang, Z.; Gu, Z.; Gao, L.; Shi, H.; Mai, L.; et al. Gastrointestinal symptoms of 95 cases with SARS-CoV-2 infection. Gut 2020, 69, 997-1001. [CrossRef] [PubMed]

8. Pan, Y.; Zhang, D.; Yang, P.; Poon, L.L.M.; Wang, Q. Viral load of SARS-CoV-2 in clinical samples. Lancet Infect. Dis. 2020, 20, 411-412. [CrossRef]

9. Giuffrè, M.; Di Bella, S.; Sambataro, G.; Zerbato, V.; Cavallaro, M.; Occhipinti, A.A.; Palermo, A.; Crescenti, A.; Monica, F.; Luzzati, R.; et al. COVID-19-induced Thrombosis in Patients without Gastrointestinal Symptoms and Elevated Fecal Calprotectin: Hypothesis regarding Mechanism of Intestinal Damage Associated with COVID-19. Trop. Med. Infect. Dis. 2020, 5, 147. [CrossRef] [PubMed]

10. Effenberger, M.; Grabherr, F.; Mayr, L.; Schwaerzler, J.; Nairz, M.; Seifert, M.; Hilbe, R.; Seiwald, S.; Scholl-Buergi, S.; Fritsche, G.; et al. Faecal calprotectin indicates intestinal inflammation in COVID-19. Gut 2020, 69, 1543-1544. [CrossRef] [PubMed]

11. Bhayana, R.; Som, A.; Li, M.D.; Carey, D.E.; Anderson, M.A.; Blake, M.A.; Catalano, O.; Gee, M.S.; Hahn, P.F.; Harisinghani, M.; et al. Abdominal Imaging Findings in COVID-19: Preliminary Observations. Radiology 2020, 297, E207-E215. [CrossRef] [PubMed]

12. De Nardi, P.; Parolini, D.C.; Ripa, M.; Racca, S.; Rosati, R. Bowel perforation in a Covid-19 patient: Case report. Int. J. Colorectal Dis. 2020, 35, 1797-1800. [CrossRef] [PubMed]

13. Gartland, R.M.; Velmahos, G.C. Bowel Necrosis in the Setting of COVID-19. J. Gastrointest. Surg. 2020, 1-2. [CrossRef] [PubMed]

14. Bielecki, K.; Kamiński, P.; Klukowski, M. Large bowel perforation: Morbidity and mortality. Tech. Coloproctol. 2002, 6, 177-182. [CrossRef] [PubMed]

15. Pouli, S.; Kozana, A.; Papakitsou, I.; Daskalogiannaki, M.; Raissaki, M. Gastrointestinal perforation: Clinical and MDCT clues for identification of aetiology. Insights Imaging 2020, 11, 1-9. [CrossRef] [PubMed]

16. Borofsky, S.; Taffel, M.; Khati, N.; Zeman, R.; Hill, M. The emergency room diagnosis of gastrointestinal tract perforation: The role of CT. Emerg. Radiol. 2015, 22, 315-327. [CrossRef] [PubMed] 
17. Furukawa, A.; Sakoda, M.; Yamasaki, M.; Kono, N.; Tanaka, T.; Nitta, N.; Kanasaki, S.; Imoto, K.; Takahashi, M.; Murata, K.; et al. Gastrointestinal tract perforation: CT diagnosis of presence, site, and cause. Abdom. Imaging 2005, 30, 524-534. [CrossRef] [PubMed]

18. Del Gaizo, A.J.; Lall, C.; Allen, B.C.; Leyendecker, J.R. From esophagus to rectum: A comprehensive review of alimentary tract perforations at computed tomography. Abdom. Imaging 2014, 39, 802-823. [CrossRef] [PubMed]

(C) 2020 by the authors. Licensee MDPI, Basel, Switzerland. This article is an open access article distributed under the terms and conditions of the Creative Commons Attribution (CC BY) license (http://creativecommons.org/licenses/by/4.0/). 